\title{
Ketahanan sistem struktur bangunan terhadap angin studi kasus : Mbaru Niang di Desa Wae Rebo, Kabupaten Manggarai, NTT
}

\author{
Eugenius Pradipto ${ }^{\text {a, }}{ }^{*}$, Kartika Tristanto ${ }^{\text {b }}$
}

a Dosen Program Studi Magister Arsitektur, Fakultas Teknik Arsitektur dan Perencanaan, Universitas Gadjah Mada. b Mahasiswa Program Studi Magister Arsitektur, Fakultas Teknik Arsitektur dan Perencanaan, Universitas Gadjah Mada. 1 e.pradipto@gmail.com*

\begin{tabular}{ll}
\hline Informasi artikel & ABSTRAK \\
\hline Sejarah artikel: & Wae Rebo merupakan salah satu desa di Kabupaten Manggarai yang \\
$\begin{array}{l}\text { Diterima } \\
\text { Revisi }\end{array}$ & berada di ketinggian I200 mdpl. Desa ini memiliki bangunan tradisional \\
Dipublikasikan & berbentuk kerucut dengan ketinggian lima belas meter yang dinamakan mbaru \\
\hline Kata kunci: & niang. Letaknya yang berada di ketinggian akan berpengaruh pada bangunan \\
Sistem Struktur & terhadap angin dimana semakin tinggi suatu tempat maka semakin besar kecepatan \\
Wae Rebo & anginnya. Namun hingga saat ini mbaru niang masih berdiri dengan fungsi yang \\
Mbaru Niang & sama sebagai tempat tinggal sejak puluhan tahun. Keterbatasan teknologi saat itu \\
Angin & membuat masyarakat Wae Rebo menggunakkan teknologi yang sederhana dalam \\
& membangun mbaru niang. Hal ini menjadikan bahasan yang menarik untuk diteliti, \\
& dimana tujuan penelitian ini adalah untuk mengetahui bagaimana ketahanan sistem \\
& struktur rumah tradisional mbaru niangyang dibangun oleh masyarakat Wae Rebo \\
& terhadap angin. Dan kondisi tersebut menjadikan masalah terhadap konstruksi \\
& bangunan yang berada di ketinggian. Metode yang digunakan pada penelitian ini \\
& bersifat kualitatif rasionalistik dengan memperoleh data studi literatur dari \\
& berbagai jurnal, selain itu juga peneliti melakukan wawancara guna mencocokan \\
& data. Hasil dari penelitian ini ditemukan penggunaan sistem struktur bangunan di \\
& mbaru niang terhadap angin dapat dikatakan tepat guna, dimana bangunan ini juga \\
memiliki struktur yang terpisah didalamnya. Serta adanya sistem struktur sendi & dan jepit sehingga dapat meminimalkan goyangan dari terpaan angin, sistem \\
tersebut diperkuat lagi dengan dengan teknik kunci dari sistem ikat yang membuat & setiap sambungan lebih fleksibel.
\end{tabular}

\section{Key word:}

Structural System

Wae Rebo

Mbaru Niang

Air

\begin{abstract}
Wae Rebo is one of the villages in Manggarai Regency which is located at an altitude of $1200 \mathrm{~m}$ above sea level, this village has a traditional cone-shaped building with a height of fifteen meters called mbaru niang, its location at that height will affect the existing buildings of this village against the wind which is getting worse. the higher a place to eat, the greater the wind speed, but until now Mbaru Niang still stands with the same function as a residence for decades. With the limitation of technology, the people of Wae Rebo used simply technology in Mbaru Niang, which is interesting topic to study, to find out how the resilience of Mbaru Niang structural system built by them can face the wind which is the problem with building construction in height. The method used in this research is rasionalistic qualitative by obtaining data from literature studies from various journal, besides that the researcher also doing interviews to match the data. The results of this study found that the building structural system in Mbaru Niang against the wind it's effective, and this building also has a separate structure in it ,uses a joint and clamp structure system, so that it can minimize swaying from wind, the system is reinforced with key techniques of the fastening system which makes each joint more flexible
\end{abstract}




\section{Pendahuluan}

Setiap suku bangsa memiliki arsitektur tradisional sebagai wujud kebudayaannya yang bertumpu pada adat istiadat dan kepercayaan yang diyakininya. Bangunan yang dihasilkan dari sebuah budaya mengasilkan sebuah bentuk yang berbeda-beda yang berterkaitan dengan suatu nilai budaya dan adat lingkungan sehingga menciptakan ciri khasnya pada setiap daerah. Arsitektur tradisional tumbuh dalam suatu masyarakat sebagai cerminan yang berkaitan dengan tempat dan waktu, sehingga dapat memberikan gambaran tentang suatu bentuk, tipologi serta ruang yang tercipta berdasarkan adaptasi alamiah pada lingkungan natural, untuk menciptakan kelarasan sosial, budaya lingkungan alam yang ada di sekelilingnya (Foster, I969:I55 dalam Rostiyati, 2013: 460). Salah satu bangunan tradisional yang cukup menarik dan memiliki ciri khas tertentu adalah bangunan tradisional di Desa Wae Rebo yang terletak di Kabupaten Manggarai, Nusa Tenggara Timur. Bentuk bangunan nya yang berbentuk kerucut dan memiliki dasar berbentuk lingkaran membuat bangunan ini berbeda dari rumah tradisional biasanya. Bangunan tradisional di Desa Wae Rebo ini dinamakan mbaru niang, hanya terdapat tujuh bangunan di desa ini yang masih digunakan sebagai tempat tinggal setiap keluarga Suku Manggarai, biasanya terdiri dari enam hingga delapan keluarga dalam satu mbaru niang. Setiap rumah memiliki kepala rumah sebagai pemimpin dalam satu bangunan rumah tetapi dalam satu desa terdapat satu kepala adat yang tinggal dalam rumah mbaru niang gedang bersama keturunannya, selain itu desa ini juga masih digunakkan sebagai tempat upacara adat. Bangunan ini memiliki ketinggian I2 hingga I5 meter. Bangunan ini berdiri diatas ketinggian I200 m diatas permukaan laut (Lanur \& Martini, 20I5) dan memiliki kondisi alam sangat sejuk cenderung dingin selain itu juga dipengaruhi letak desa yang berada di tengah cekungan bukit dan dikelilingi oleh bentang alam berupa perbukitan (Keling, 2016).

Letak Desa Wae Rebo yang berada di ketinggian menjadikan masyarakatnya akan beradaptasi terhadap angin, dimana semakin tinggi letaknya, semakin ekstrim anginnya. Ketinggian suatu tempat dari permukaan tanah akan mempengaruhi kecepatan angin pada tempat tersebut, semakin tinggi posisi bangunan dari atas permukaan tanah, semakin cepat pula kecepatan angin yang diterima oleh bangunan tersebut (Susanto, dkk., 20I5). Berdasarkan data informasi bencana Indonesia Badan Nasional Penanggulangan Bencana (BNPB) letak geografis Manggarai berada pada wilayah bencana gempa serta didominasi cuaca ekstrim atau angin puting beliung. Karena letaknya yang berada di ketinggian, desa ini lebih beresiko terhadap bencana angin. Hal ini dapat mempengaruhi bangunan yang terdapat di Desa Wae Rebo, dimana bangunan di Wae Rebo yang termasuk bangunan tradisional telah ada dari berpuluhpuluh tahun lamanya, dibangun dengan teknologi dan sistem struktur yang sederhana oleh nenek moyang mereka.

Dengan teknologi dan sistem struktur sederhana ini menjadikan hal yang menarik untuk dibahas yang bertujuan untuk mengetahui bagaimana ketahanan sistem struktur rumah tradisional mbaru niang yang dibangun oleh masyarakat Wae Rebo terhadap angin yang menjadi suatu masalah terhadap konstruksi bangunan yang berada di ketinggian dimana perlu adanya suatu penelitian tentang bentuk sistem struktur yang di gunakan untuk menanggulangi angin kencang yang pada setiap waktu akan muncul. Sehingga penelitian ini dapat menjadi suatu informasi yang berguna untuk memperdalam ilmu dalam mengatasi masalah di lingkungan terhadap bangunan dengan teknologi yang sederhana.

\section{Metode}

Penelitian ini menggunakan metode rasionalistik dengan pendekatan deskriptif kualitatif. Menurut Djunaedi (I989) dalam Sarminta (20I5), metode rasionalistik biasanya bertujuan untuk menemukan sesuatu, bukan untuk menguji suatu teori. Data yang didapat pada penelitian ini berasal dari studi literatur dari berbagai jurnal dan beberapa artikel terkait selain itu juga peneliti melakukan wawancara guna menambahkan informasi data dan juga menambah informasi dalm mencocokan data yang sebelumnya didapat.

\section{Hasil dan Pembahasan}

\section{A. Bentuk dan Konsep Tata Ruang Mbaru Niang}

Bangunan tradisional di Indonesia pada umummnya menggunakkan konsep makro kosmos, hal itu juga ditemukan di Desa Wae Rebo, dimana terdapat tiga bagian didalamnya, yaitu ruang bawah atau kolong atau biasa disebut dengan kaki, kemudian diatasnya sebagai wadah manusia beraktivitas disebut dengan ruang tengah atau badan, dan bagian atas dari ruang aktivitas merupakan ruang atas atau kepala yang merupakan ruang dari bagian atap, dimana bagian ini berhubungan dengan kepercayaan akan leluhur dan Tuhan mereka. 


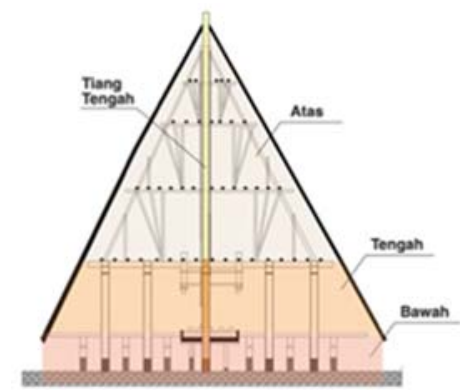

Gambar I I. Pembagian Ruang Mbaru Niang

Sumber: Analisa Penulis, 2020

Ruang bawah pada mbaru niang merupakan kolong bangunan dimana hewan peliharaan diletakan serta biasanya saat siang hari para wanita akan menenun di pinggiran kolong ini. Kemudian ada ruang tengah yang merupakan ruang aktivitas manusia, disini terdapat kamar-kamar penghuni masing-masing keluarga, dapur serta ruang bertamu.

Pada lantai satu ini dibagi menjadi dua bagian yaitu ruang privat dan ruang publik, dimana dipisahkan dengan tungku yang berada di tengah ruang, para wanita biasanya beraktivitas di dapur atau di sekitar tungku sedangkan para lelaki biasanya beraktivitas di depan, dekat pintu masuk. Pada ruang tengah ini disangga dengan Sembilan tiang utama yang dimana merupakan konsep struktur dari mbaru niang itu sendiri, tiang ini terpisah dengan lantai di atasnya.

Pada bagian ruang atas/ atap terdiri atas empat tingkatan lagi, yang terdiri dari lobo (tingkat 2) yang berfungsi sebagai tempat menyimpan barang-barang dan hasil panen, lentar berfungsi sebagai tempat menyimpan benih-benih tanaman (tingkat 3), lempa rae (tingkat 4) sebagai wadah menyimpan stok makanan ketika kekeringan, hekang kode (tingkat 5) sebagai tempat menaruh sesajian persembahan kepada leluhur.

Semua ruang ini disatukan dengan satu tiang tengah yang merupakan salah satu dari tiang utama, tiang ini menjulur dari bawah hingga ke atas atau puncuk bangunan. Tiang ini dianggap tiang suci oleh masyarakat Wae Rebo karena fungsinya sebagai poros dari bangunan ini. Di dalam mbaru niang tiang tengah menjadi pusat dimana semua aktivitas mengarah ke tiang tengah, seperti saat tidur, posisinya badan mengarah ke tiang tengah, kemudian jika ada acara di dalam mbaru niang, masyarakat akan duduk melingkar dan sebagai pusat adalah tetua adat yang berada di depan tiang mengahadap kearah pintu.

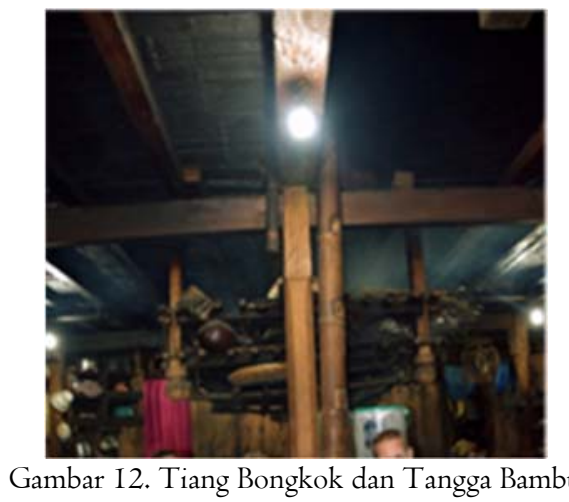

Sumber: Indohollandtours, 2017

Pada tiang tengah ini dari tingkat pertama diikat sebuah tangga yang terbuat dari bambu yang disebut rede, berfungsi untuk penghuni mencapai tingkat atas. Pada tiang tengah secara keseluruhan tidak menggunakkan satu kayu yang menerus dari tanah hingga ke atas, melainkan terdapat dua buah kayu bagian yang menyambung yaitu, hiri bongkok pada bagian tengah menerus dari bawah atau kolong hingga ke tingkat pertama, dan tiang ngando pada tingkat kedua hingga ke paling atas.

Lantai mbaru niang ini berbentuk lingkaran dari yang besar dengan diameter $\mathrm{I} 4 \mathrm{~cm}$ kemudian mengecil pada setiap bagian diatasnya, hal ini mempengaruhi bentuk dari bangunan keseluruhan mbaru niang, dimana bangunan ini memiliki bentuk yang kerucut. 


\section{B. Pengaruh Angin terhadap Bentuk Bangunan di Mbaru Niang}

Mbaru Niang di Wae Rebo memiliki bentuk kerucut dimana bangunan ini memiliki bagian yang besar di bawah dan mengecil pada bagian atasnya. Bentuk kerucut ini merupakan keseluruhan dari atap dan dinding yang menyelubungi bangunan mbaru niang dari puncuk paling atas hingga bagian bawah mbaru niang dimana bagian bawah ini hampir menyentuh tanah, sehingga keseluruhan bangunan ini tidak memiliki bentuk lain pada bagian luar permukaan bangunan.

Pengaruh bentuk struktur bangunan segitiga dan runcing terhadap angin dapat dikatakan stabil dari berbagai arah. Bentuk runcingnya yang tidak memiliki bentuk yang besar melainkan lebih kecil dari bagian bawahnya pada atap dapat mengatasi angin yang kemungkinan dapat berputar dimana Desa Wae Rebo dikelilingin oleh tujuh bukit disekitarnya yang memungkinkan hal tersebut terjadi.

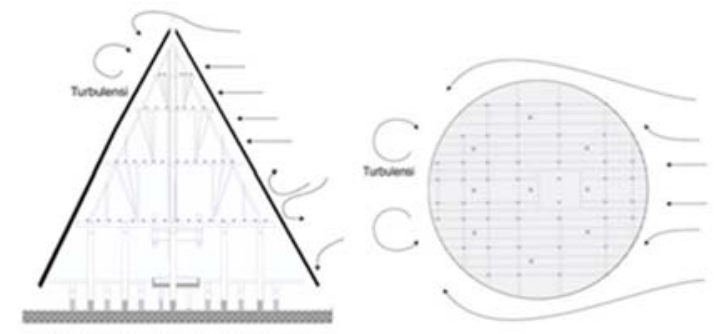

Gambar 13. Pengaruh Benuk Mbaru Ninag terhadap Angin Sumber: Analisa Penulis, 2020

Bangunan ini memiliki bagian atas yang lebih kecil, sehingga pengaruh tekanan angin pada bangunan ini bekerja lebih ringan dibanding bagian bawah yang lebih besar, sehingga pada ketinggian bangunan ini akan berpengaruh kecil terhadap gaya angin.

Selain itu, bentuk atap yang hampir menyentuh tanah juga merupakan usaha untuk menanggulangi adanya tekanan dari angin besar diluar bangunan agar atap tidak terangkat. Kecepatan maksimum angin akan berada di atas bangunan dan angin yang bergerak dibawah bangunan akan diserap oleh pepohonan sehingga angin yang bergerak di sekitar bawah bangunan tidak sebesar angin di atas bangunan.

Maka dari itu, dengan kerapatan antara atap dengan tanah dibawahnya akan meminimalisir lagi angin yang datang secara horizontal dari luar dan tidak akan langsung masuk ke dalam rumah sehingga peluang atap tersebut terangkat akan sedikit.

\section{Sistem Struktur dan Konstruksi Mbaru Niang terhadap Angin}

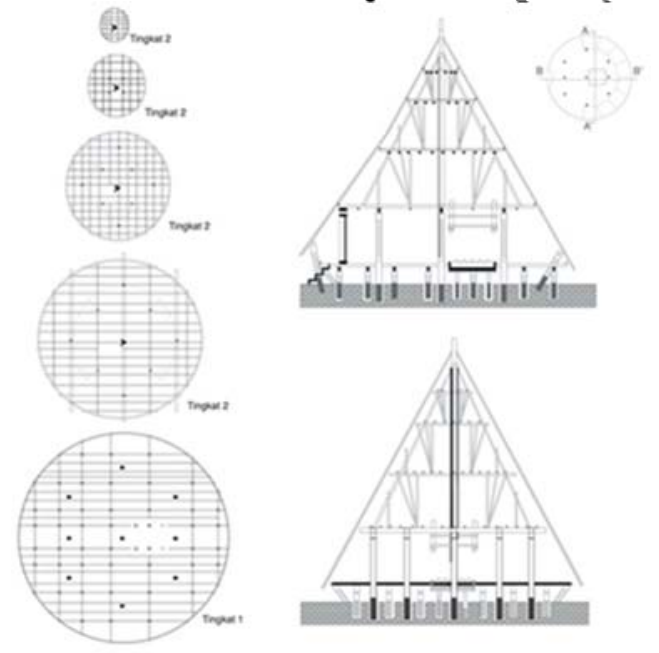

Gambar 14. Denah dan Potongan Struktur Mbaru Niang Sumber: Analisa Penulis, 2020 
Mbaru niang memiliki struktur yang terpisah pada bagian ruang tengah dan bagian ruang atasnya, hal ini teridentifkasi dari struktur sembilan tiang yang terdapat pada ruang tengah yang disangga oleh sembilan tiang tersebut. Ke sembilan tiang ini tertanam langsung ke dalam tanah yang menerus hingga menyangga balok lantai tingkatan ke dua. Tiang ini akan berhenti pada tingkatan tersebut sehingga strukturnya tidak memiliki hubungan dengan bagian ruang diatasnya.

Ruang tersebut akan di satukan dengan tiang tengah sebagai satu tiang penyatu antara ketiga tingkatan ruang, ruang kolong, ruang tengah dan ruang atas, didalam mbaru niang yang di sebut dengan tiang bongkok. Tiang bongkok merupakan salah satu dari sembilan tiang utama yang berada di tengah-tengah. Ketinggian dari sembilan tiang ini sama sampai ke lantai ruang atas, tiang bongkok ini disambung sampai ke ujung bangunan, yang dinamakan dengan tiang ngando.

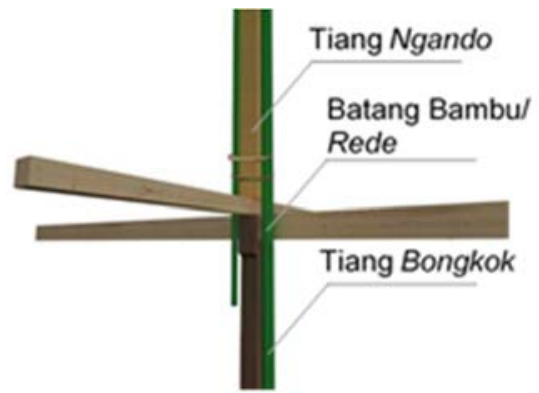

Gambar 15. Letak Tiang Bongkok dan Tiang Ngando Sumber: Analisa Penulis, 2020

Tiang ngando dan dan tiang bongkok di sambung dengan sistem sendi. Dan diperkuat dengan cara di apit oleh dua batang bambu. Posisi batang bambu berada separo dari tiang bongkok dan difungsikan sebagai anak tangga untuk naik ke ruang atas atau ujung atap bangunan. Untuk memperkuat dan menstabilkan posisi tiang ngando agar tidak bergeser diperkuat oleh empat batang miring arah mata angin (pengga ngando) yang bertumpu pada balok lantai ruang atas. Penerusan gaya-gaya ini di ambil alih oleh ke empat batang tersebut. Sehingga tiang ngando hanya sebagai tiang penegak bukan sebagai tiang tumpuan.

Peletakan sistem sambungan bongkok dan tiang ngando pada bagian lantai ruang atas memberikan reaksi yang fleksibel terhadap gaya-gaya dari luar yang akan di terima oleh ke empat batang miring. Sehingga sambungan sendi diperlukan untuk memperkecil gaya tekuk batang dibandingkan jika batang menerus dari ujung tanah sampai ke ujung. Posisi sambungan sendi pada tiang ngando dan tiang bongkok yang berada di tiang tengah mampu meredam gaya angin dari atas, gaya akan ternetralisir di titik sambung dan tidak diteruskan ke tiang bongkok. Dengan demikian sembilan tiang utama mbaru niang tetap dalam keadaan stabil tidak mengalami beban dari gaya angin.

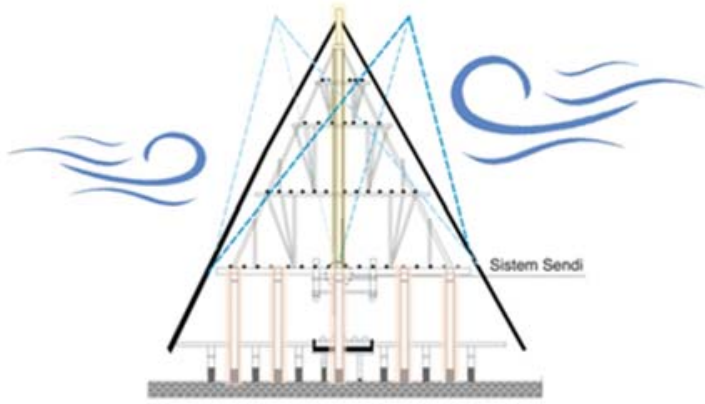

Gambar I6. Pengaruh Angin terhadap Struktur Atas Sumber: Analisa Penulis, 2020

Bagian ruang tengah ditumpu oleh sembilan tiang utama, dengan tiang bongkok sebagai centemya, sembilan tiang ini tertancap ke dalam tanah dan diatasnya disatukan dengan balok-balok lantai dan ujung tiang bagian atas di satukan dengan balok lantai-lantai ruang atas. Lantai ruang bagian tengah di konstruksi terpisah dari sembilan tiang utama.

Dengan pemisah konstruksi lantai dan tiang utama menjadikan posisi lantai ruang tengah sebagai ruang tinggal tidak akan di pengaruhi oleh gaya dari atas. Lantai ruang tinggal 'hanya' akan dipengaruhi oleh gaya dari bawah, atau mungkin gaya gempa. Gaya yang menimpa sembilan tiang tidak akan berpengaruh secara langsung terhadap struktur lantai pada ruang tinggal atau ruang tengah. Dengan demikian, lantai ruang tinggal akan memiliki stabilitas 
yang tinggi, tanpa tersentuh secara langsung terhadap gaya angin dari luar ataupun akibat dari gaya-gaya yang diterima dari struktur utama.

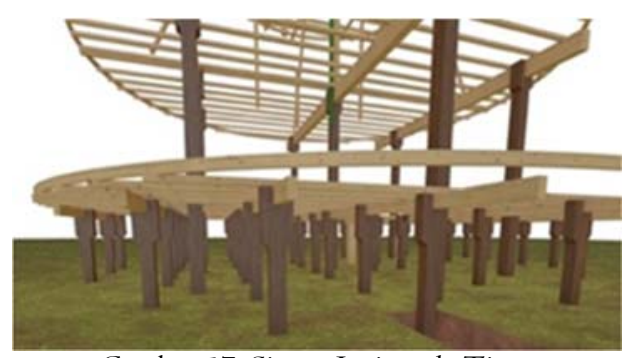

Gambar 17. Sistem Jepit pada Tiang

Sumber: Analisa Penulis, 2020

Sistem struktur pondasi yang digunakan pada Mbaru Niang adalah sistem ceblokan, atau sistem jepit menurut Frick (I997) dengan sistem ceblokan menjadi ponasi yang terjepit terbatas. Sistem jepit ini cukup asing pada bangunan tradisional yang biasanya menggunakkan sistem pondasi umpak atau sendi. Sistem sendi memang banyak digunakkan pada masalah kelembapan tanah namun utamanya adalah mengatasi gaya gempa agar tidak terlalu cepat naik ke tiang atas. Dengan sistem ceblokan ini kurang menguntungkan untuk antisipasi gaya gempa dan juga terhadap serangan dari inscta. Dengan demikian terlihat bahwa sistem ceblokan bukan mengatasi gempa melainkan untuk mengantisipasi gaya angin yang akan menggeser dan mengangkat bangunan, dimana gaya angin lebih banyak dan lebih sering dan kemungkinan lebih besar ditemui di daerah yang berada di atas bukit.

\section{Sistem Sambungan dan Kuncian}

Sistem sambungan konstruksi antara batang dan usuk menggunakkan cara sambungan yang menempel, yaitu tanpa harus purus atau di coak, dimana sambungan tersebut membuat kayu tetap utuh, sehingga kayu memiliki kekuatan yang penuh. Dalam konstruksi ini sambungan antara kayu dengan kayu di satukan dengan alat sambung tali atau dengan sistem ikat.

Sambungan batang-batang kayu di mbaru niang menggunakkan sistem ikat, dimana sistem ikat memiliki suatu kelebihan yaitu fleksibel, dapat kuat terhadap gaya tarik dan gaya tekan termasuk juga dengan gaya geser. Cara ikat yang digunakkan di wae rebo lebih kuat dari pada sistem sambungan pasak atau baut yang kaku dan merusak kayu yang kemungkinan akan patah dan sobek pada kayunya. Sistem sambungan ikat menurut Schorder (2006) dinamakan dengan square lashing, diagonal lashing dan Plais strip.
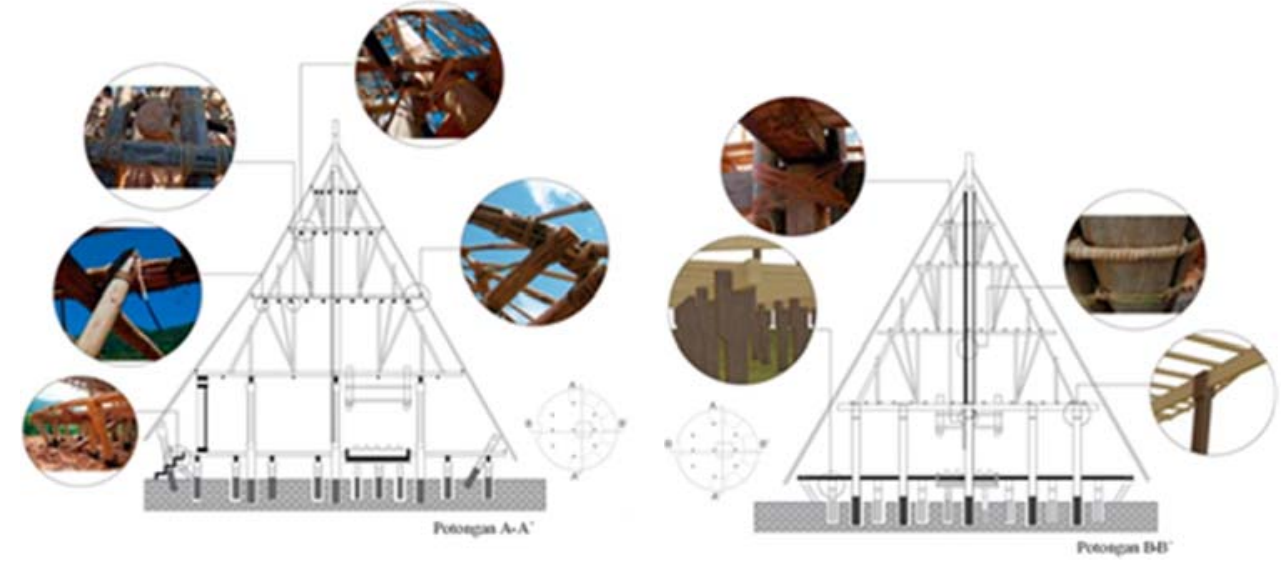

Gambar 18. Sistem Ikat Mbaru Niang

Sumber: Analisa Penulis, 2020

Di mbaru niang jenis sistem sambungan ikat ini di terapkan dengan beberapa jenis yaitu, jenis square lashing yang salah satunya digunakkan pada pertemuan hiri atau tiang yang miring pada tingkat dua, tiga dan empat (ruang atas) untuk menahan struktur lantai atasnya, selain itu jenis diagonal lashing paling sering ditemukan yang merupakan teknik yang di ikatkan secara diagaonal, dimana terdapat pada pengikatan struktur lantai, pada tiang (kolom) dan balok serta pada penahan bambu di tiang bongkok. 
Selain teknik ikat jenis square lashing dan diagonal lashing, juga ditemukan jenis plaits strip, yaitu tali rotan yang digulung sejajar, jenis ini ada pada teknik ikat tiang ngando yang diapit oleh bambu di kanan dan kirinya agar memperkuat tegakannya. Sehingga, dengan teknik yang fleksibel ini pertahanan teknik ikat terhadap angin hanya akan bergesek kecil namun tidak berpindah tempat, menjadikan teknik ikat ini lebih tepat digunakkan.

\section{Simpulan}

Dari pembahasan diatas dapat disimpulkan jika sistem struktur mbaru niang dapat bertahan pada ketinggian dengan kemungkinan dari kecepatan angin yang ada di Wae Rebo. Dimana bangunan mbaru niang menggunakan sistem struktur yang tepat guna. Hal tersebut dapat dibuktikan dari penerapan sistem struktur terpisah pada tiang tengah yang merupakan sistem sendi yang ada pada ruang tengah dan ruang atas. Sistem ini akan memperkecil kemungkinan bergoyangnya suatu struktur jika terkena terpaan angin pada ruang tinggal, hal ini juga dipengaruhi oleh sistem struktur yang menopang dengan pondasi ceblokan yang ada pada tiang-tiang struktur dan sistem jepit pada pertemuan balok dan tiang (kolom).

Selain itu sistem teknik ikat juga mempengaruhi bangunan agar bergerak fleksibel sehingga jika terkena terpaan angin sambungan tidak akan patah. Sistem struktur ini dapat dikatakan teknologi yang tepat guna, dimana bangunan yang berdiri dari puluhan tahun lamanya masih bertahan hingga saat ini dengan teknologi yang sederhana dan mampu beradaptasi dengan masalah yang ada di sekitarnya

\section{Referensi}

AY, Nur Ikhsan. (2020). Studi Karakteristik Mekanik Kawat Bronjong Untuk Menahan Sedimen. Jurnal Teknik Sipil MACCA, 5(3), 201-209.

Beeh, Y. Y. (2017). The role of community in the development of Wae Rebo as a community-based tourism destination in East Nusa Tenggara. Journal of Business on Hospitality and Tourism, 3(I), 55-79.

Damayanti, D. P., \& Suprijanto, I. (2012). Penguasaan Teknologi Struktur dan Konstruksi Bangunan Tradisional Manggarai sebagai Kunci Keberhasilan dalam Upaya Pelestarian. Jurnal Lingkungan Binaan Indonesia, I(I), 75-85

Faoji, a., \& Sambowo, k. A. (2018). Perbandingan tumpuan jepit dan sendi pada struktur power house ditinjau dari segi efisiensi material dan biaya (studi kasus proyek pltmg seram peaker). Jurnal infrastruktur, 4(2), I I9-I26.

Fardheny, A. F. (2016). Simulasi Pembebanan Gaya Angin pada Baliho Berdasarkan Kode Pembebanan Peraturan Muatan Indonesia dan British Standard BS6399. INFO-TEKNIK, 8(2), 87-92.

Frick, I. H. (20I4). Konstruksi Arsitektur 7 ilmu konstruksi bangunan bambu, Pengantar Konstruksi Bambu (Vol. 7). Kanisius.

Keling, Gendro. 2016. Kearifan Budaya Masyarakat Kampung Tradisional Wae Rebo, Manggarai, Nusa Tenggara Timur. Jurnal Penelitian Sejarah dan Nilai Tradisional, 23(I).

Lanur, V. S., \& Martini, E. (2015). Pengembangan Desa Wisata Wae Rebo Berdasarkan Kearifan Lokal. Planesa, 6(2), 6066.

Rinaldi, Z., Purwantiasning, A. W., \& Nur'aini, R. D. (2015). Analisa Konstruksi Tahan Gempa Rumah Tradisional Suku Besemah di Kota Pagaralam Sumatera Selatan. Prosiding Semnastek.

Roosandriantini, Josephine. (2018) Terapan Trilogi Vitruvius Dalam Arsitektur Nusantara. Jurnal Arsitektur EMARA, 4(2), 77-84.

Rostiyati, Ani. (2013). Tipologi Rumah Tradisional Kampung Wana di Lampung Timur. Jurnal Patanjala, 5(3),460.

Santoso, V. G., \& Anandhita, G. (2020). Pemanfaatan Botol Plastik untuk Sambungan Ikat pada Konstruksi Bambu. IPLBI, 64-7I.

Sarmita, I. M. (20I5). HUMAN RESOURCES DEVELOPMENT PLANNING (LABOR) INDONESIA. Media Komunikasi Geografi, I6(2).

Schroder, Stephane. (2015). Durability of Bamboo.

Sentra Edukasi. 2020. Mengenal Cuaca Angin. Sentra Edukasi Media, Yogyakarta.

Sholehudin, Asrori. (2019). Bahaya angin lesus. Loka Aksara,Tangerang.

Susanto, J., Dafik, D., \& Fatahillah, a. (2015). Analisis kecepatan aliran udara pada gedung bertingkat karena pengaruh penghalang di depannya. Kadikma, 6(2).

https://genpi.id/rumah-adat-mbaru-niang-di-wae-rebo-manggarai/ (Diakses pada 20 Oktober 2020 pada pukul I7.I I)

https://indohollandtours.blog/2017/09/02/tujuh-rumah-adat-berbentuk-kerucut-milik-desa-waerebo-flores/ (Diakses pada I4 Oktober 2020 pada pukul I3.05) 